\title{
Governance of risk management programs: Learning from Québec's Farm Income Stabilization Insurance program
}

\author{
Frédérick Clerson * \\ University of Arkansas
}

Submitted June 1, 2021 / Revised September 3 and October 28, 2021 / Accepted October 29, 2021 /

Published online February 25, 2022

Citation: Clerson, F. (2022). Governance of risk management programs: Learning from Québec's Farm

Income Stabilization Insurance program. Journal of Agriculture, Food Systems, and Community Development,

11(2), 217-234. https://doi.org/10.5304/jafscd.2022.112.011

Copyright (C) 2022 by the Author. Published by the Lyson Center for Civic Agriculture and Food Systems. Open access under CC-BY license.

\begin{abstract}
Involving stakeholders in program decision-making can support existing programs and reduce tensions against the state. However, to be involved, stakeholders may request specific mechanisms to influence program design or outcomes. This paper analyzes the design of four consultation mechanisms and the resultant stakeholder experiences in a provincial Canadian program called Farm Income Stabilization Insurance (FISI). The program offers a protection against low prices. The findings of this paper are based on 18 semi-structured interviews conducted with current and former participants familiar with the mechanisms. An analysis is
\end{abstract}

* Corresponding author: Frédérick Clerson, Ph.D. candidate, Department of Public Policy, University of Arkansas; 1 University of Arkansas; Fayetteville, AR 72701 USA; +1-514-217-5525; fclerson@email.uark.edu

\section{Author Note}

A preliminary version of this paper was presented at the $2^{\text {nd }}$ Agriculture Policy Research Group Annual Conference, October 2020. accomplished through Arnstein's ladder of citizen participation and Glasser's choice theory. Results show that stakeholder representation can be improved by adequately designing consultation mechanisms and implementing specific actions. Recommended practices include separating political and technical discussions, asking a third party to take charge of the consultation mechanisms and prepare information, formally laying down recurrent mechanisms, and involving high-ranking individuals in the discussions.

\section{Keywords}

Stakeholder Participation, Agriculture Governance, Farm Income Stabilization Insurance, Assurance stabilisation des revenus agricoles

\section{Disclosure}

The author worked at Centre d'Études sur les Coûts de Production en Agricul $\neg$ ture (CECPA)during the editing of this article, in a division that did not address Farm Income Stabilization Insurance (FISI), nor FISI-related activities. The underlying study behind this article and the first version of the article were written prior to any engagement with the CECPA. 


\section{Introduction}

Designing government-sponsored programs involves many factors. These include budget considerations, stakeholders' needs and demands, and the potential impact of the program on the environment, on society, or on other groups that may expect to receive similar support (Bellemare \& Carnes, 2015; Daugbjerg \& Swinbank, 2012; Josling, 2002; Mercier, 2016; Skogstad, 2008). Ideally, policymakers who design government programs rely on many sources of information to make sound decisions, leading to the efficient distribution of funds, thus achieving their primary objective of benefitting stakeholders.

Many of these funding decisions are based on data gathered by bureaucrats working with existing programs (Kelman, 2005; Lindblom, 1959). While this type of data is valuable, primary beneficiaries of programs also have knowledge and information that could influence the decision-making process (Gailmard \& Patty, 2013). One way to access beneficiaries' input is to engage interest groups through the lobbyists who represent them and serve as their voice. This mechanism could convey information directly from interest groups to politicians and the state (Baumgartner et al., 2009).

The case study presented here showcases such a relationship regarding the design and implementation of one provincial risk management program in Canada, the Farm Income Stabilization Insurance $(\text { FISI })^{1}$ program. This study enables the identification of factors supporting stakeholder participation and contributes to a better understanding of FISI, a program that has historically lacked attention from researchers (Gervais \& Larue, 2007). Informational considerations are especially important for this program since problematic information can yield additional risks for farmers (Antón et al., 2011).

Drawing on Arnstein's (1969) ladder of citizen participation and Glasser's (1999) choice theory, this paper examines the involvement of Québec farmers in decisions affecting the FISI program through mechanisms of consultation, where farmers' groups have a voice in the establishment of parameters surrounding the program and the eligibility of the beneficiaries. This specific combination of theories creates a framework covering the formal aspects of consultation and the interactions between stakeholders inside and around these consultations. Furthermore, it also addresses the relationship between beneficiaries' representatives and the state. By focusing on the relationship rather than the use of power or resources, this approach departs from the more traditional perspective of interest representation in some political science and public policy theories (see Bachrach \& Baratz, 1962; Cawson, 1986; Cobb \& Ross, 1987; Dahl, 1961; Kanol, 2015).

This research relies on an outcome evaluation of the mechanisms of consultation, particularly through expert interviews, to increase our understanding of how farmers' groups are incorporated into program decision-making.

The results suggest that since the early 2000s, when the state implemented these mechanisms of consultation, tensions related to risk management programs between the state and farmers' groups have lessened in Québec. The process has led to a climate of collaboration rather than one of mistrust and confrontation. The results also identify certain aspects of mechanism design that can foster participation.

This paper first includes a section presenting how Arnstein's ladder of citizen participation and Glasser's choice theory can be combined to inform farmer participation in the program decisionmaking process. A second section describes the FISI program and the mechanisms of consultation used to inform and update program parameters. A third section discusses the use of outcome evaluation and expert interviews to assess the utility of the mechanisms as perceived by the participants. Finally, the fourth section concludes with the results of this assessment, as well as the patterns that emerged that support sustaining stakeholder participation.

\section{Stakeholder Involvement in Program Decision-making}

This study focuses on the interaction between stakeholders' representatives via specific FISI

\footnotetext{
${ }^{1}$ In French: Assurance Stabilisation des Revenus Agricoles (ASRA).
} 
mechanisms of consultation. The study adopts a combined perspective of individual participation and mechanism design by combining Arnstein's ladder of citizen participation and Glasser's choice theory.

In 1969, Sherry Arnstein developed a ladder representation of citizen involvement in decisionmaking processes, illustrating stakeholders' roles in the process and their level of influence. The ladder is focused on the capacity of citizens to gain power inside the institution in which they are involved through political mechanisms, such as lobbying (Collins \& Ison, 2009). The theory considers that the greater importance given to consultation participants, the greater influence stakeholders will have. The visual manifestation of the theory is a ladder composed of several rungs that stakeholders can climb to acquire more power. Each rung is cumulative with precedents equalizing the relationship between participants and the organization in charge of the consultation. For instance (see Table 1), lower rungs of participation are associated with actions of manipulation or therapy. On these rungs, stakeholders are not asked about their position on the topic but rather to participate and learn the right attitude toward the organization's actions. Therefore, consultation mechanisms placing stakeholders on these rungs limit stakeholders' influence and participation. Stakeholders are included in proper consultation mechanisms for the middle rungs, but usually as information receivers rather than actual contributors. Finally, the higher rungs of participation include partnership development, with the delegation of some power and control of the organization held by stakeholders. Participants are recognized as contributors on these rungs, and their perspective is heard. Thus, according to Arnstein (1969), by identifying which rung represents the involvement of stakeholders in decisionmaking processes, it is possible to depict who is actually making the decisions. The higher the rung that stakeholder reaches, the more power they have to influence decision outcomes.

Even though this ladder is over 50 years old, it is still regularly used by researchers from a wide variety of fields (e.g., health care, urban planning, public administration, climate change) (Collins \& Ison, 2009; Schively Slotterback \& Lauria, 2019; Stelmach, 2016; Tritter \& McCallum, 2006). In agriculture, Beyuo (2020) used Arnstein's ladder to understand how the level of engagement by farmers in non-governmental organizations (NGOs) influences their adoption of sustainable agronomic practices.

Arnstein's ladder is a useful and appropriate tool to analyze and criticize public participation mechanisms as it focuses on the access and influence provided to stakeholders' representatives (Blue et al., 2019). This theory also allows us to consider multiple stakeholders in different mecha-

Table 1. Ladder of Citizen Participation in Instances Organized by Another Actor

\begin{tabular}{cll}
\hline Rung & Rung name & Maximum stakeholder power allowed for each rung \\
\hline 1 & Manipulation & Information provided to change their opinion \\
2 & Therapy & Accompanied by professionals that can diagnose their problem \\
3 & Informing & Reception of information to increase their knowledge \\
4 & Consultation & Inclusion in committees that have no decision-making power \\
5 & Placation & Inclusion in decisional committees but without resources allowing them to be relevant \\
6 & Partnership & Share the decision-making power \\
7 & Delegated Power & Have delegated power to make decisions \\
8 & Citizen Control & Have the sole control of the programs overseen \\
\hline
\end{tabular}

Source: Arnstein, 1969. 
nisms, thus limiting potential influences from individual participant characteristics if the unit of analysis is kept at the mechanism of consultation level rather than at the individual stakeholder level (Stelmach, 2016; Tritter \& McCallum, 2006). Furthermore, by using this theory, it is possible to do a first screening to qualify the place given to stakeholders in each mechanism.

However, Arnstein's ladder of citizen participation also has some serious limits, such as assuming a linear relationship between influence and place granted in consultation mechanisms (Blue et al., 2019; Collins \& Ison, 2009). For instance, it assumes that citizen control is the best possible participation process, even if it might not align with participants' rationale, expectations, or capacity (Tritter \& McCallum, 2006). Moreover, the framework considers that each stakeholder in a group is similar, obscuring the place of minorities (Blue et al., 2019; Tritter \& McCallum, 2006).

To alleviate some of these limits, this paper adds a second theory, Glasser's (1999) choice theory, which allows a deeper examination of the aspects influencing relations in the mechanisms of consultation. It is a psychiatric theory explaining the behavior and motivation of individuals through their attempt to fulfill their needs (Milford \& Kiddell, 2020). It posits that individuals act out of unhappiness rather than mental illness. Thus, an individual's actions can be explained by understanding the relationship between their current situation and the expected ideal situation. From a psychiatric perspective, it includes the concept that fulfilling the basic needs of individuals should be the core focus of intervention rather than medicating mental illnesses (Lyngstad, 2020; Milford \& Kiddell, 2020). Glasser stipulates that individuals are constantly trying to change their situation to align it with their perceived ideal situation. Thus, individuals are incentivized to adjust their behaviors to fulfill their needs rather than palliating their symptoms (Brown et al., 2007; Glasser, 1999; Tanrikulu, 2014). In terms of consultation mechanisms, it would mean that changing the design of a mech- anism could help shift the actual situation of participants toward their ideal one.

This broad theory has mostly been applied in educational settings and has focused on mental health issues. Though, as Bjornstad (2009,p.69) mentions, there is interest in adapting Glasser's theory to a political perspective since individuals also try to fulfill their goals in these situations: "Although choice theory and assessment of needs has mostly focused on intimate relationships and/or professional relationships within education, there is no explicit theoretical limitation that prohibits these principles from being applied to political relationships." Therefore, this study adjusts Glasser's (1999) choice theory to apply it to organization and mechanisms of consultation.

Following this theory, participants in the mechanisms of consultation seek to fulfill four basic needs: belonging, power, freedom, and fun. ${ }^{2}$ Here, belonging refers to the capacity of an organization to make its stakeholders feel included and understood. Similarly, power refers to the ability of stakeholders to control their environment and influence other stakeholders in the decision-making process. In this case, during consultation meetings, the organization must ensure that the decisions made have an impact. Freedom refers to the capacity of stakeholders to express their opinion and assume the consequences of these opinions. The organization must then avoid restraining stakeholders' expression of any ideas or avenues of reflection. Finally, fun refers to the pleasure stakeholders feel when they participate in the mechanism's activities. For any organization, fun can be reached by ensuring that the other fundamental needs are fulfilled (Glasser, 1999; Seriès, 2012).

When participants cannot fulfill their needs, they should feel some discomfort or pain (Howatt, 2012). Applied to the mechanisms of consultation, and leading back to Arnstein's view, the decisionmaking control exerted by some individuals can create a poor relationship in which participation can hardly be reached (Bjornstad, 2009; Edwards, 2009; Tanrikulu, 2014). Thus, by understanding if

\footnotetext{
${ }^{2}$ A fifth one, survival, was developed by Glasser (1999) to refer to the physiological needs of survival, nourishment, and shelter. Following the work of Bjornstad (2009) and Seriès (2012), this study omits survival as it refers to actions outside of the scope of the mechanisms of consultation.
} 
and how participants' needs are fulfilled in the context of a mechanism of consultation, it would be possible to infer a participant's situation. Combining both theories creates a framework that encompasses the influence of procedures and informal rules and habits between participants (Seriès, 2012).

\section{The Farm Income Stabilization Insurance (FISI) Program}

FISI was established in the province of Québec in 1975 with the primary objective of reducing farm income variation while guaranteeing a net positive income for farmers (Commission sur l'Avenir de l'Agriculture et de l'Agroalimentaire du Québec, 2008; Groupe de Travail sur la Sécurité du Revenu, 2014; St-Pierre, 2009). It was first implemented to support cow-calf production and has since been expanded to most of the important commodities produced in Québec that are not covered by supply management (Gervais \& Larue, 2007; Lachappelle, 2007).

The program acts as insurance against market price fluctuations that would cause losses to farm-

\section{Figure 1. The Farm Income Stabilization Insurance Mechanisms of Compensation}

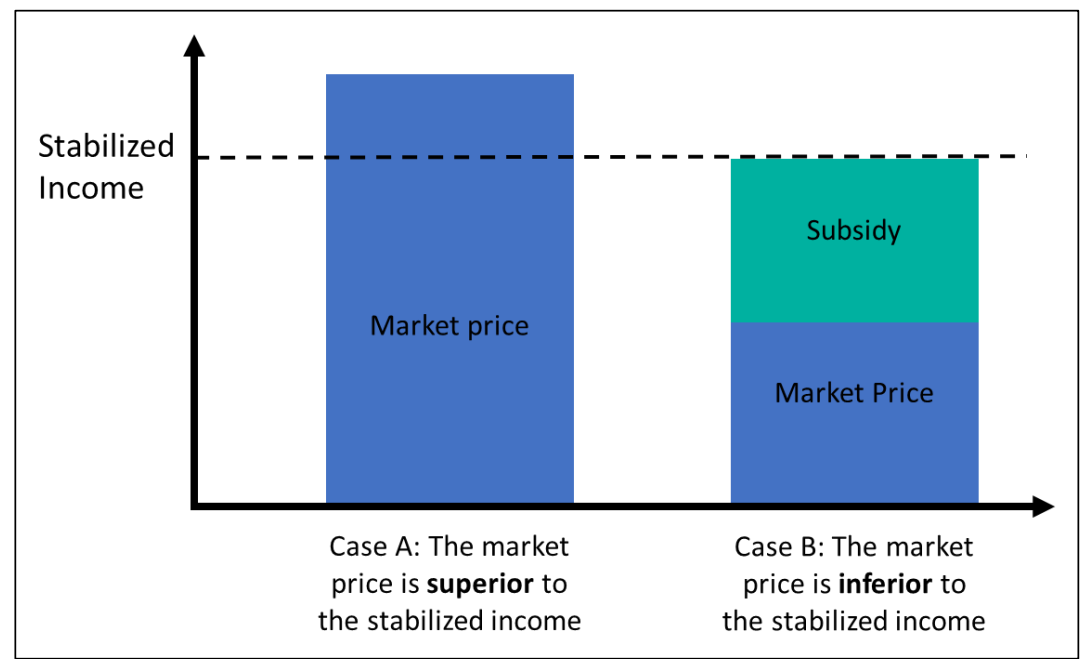

Source: Author. ers. Farmers pay a premium every year to enroll in FISI and receive a payment from the government if the market price is below the stabilized income. Hence, if the annual average market price is higher than or equal to the stabilized income, the producer receives nothing from the state (see Case A from Figure 1). If it is lower, the producer receives the difference between the stabilized income and the market price (see Case B from Figure 1) (FADQ, 2018). ${ }^{3}$ There is a different stabilized income for each of the 10 commodities covered (hogs, lamb, cattle, apples, ${ }^{4}$ and different cereals). In this sense, it is a classic protection program against low commodity prices, similar to the counter-cyclical payments included in the U.S. farm bill from 2002 to 2013 (Smith \& Glauber, 2019).

The determination of the threshold for payment is the main difference between FISI and similar programs in the United States. The stabilized income threshold represents the actual price producers should receive if the market adequately covers their cost of production. It is determined by a production cost study that the Financière Agricole du Québec (FADQ) carries out through an independent nonprofit organization, the Centre d'Études sur les Coûts de Production en Agriculture (CECPA). ${ }^{5}$ This study is conducted every five years through mandatory audits on a sample of farms producing the commodities, resulting in a model farm on which the FADQ bases all its calculations, such as the number of units produced and the production of non-FISI commodities.

Central to this paper is the idea that the determination method of each element of the stabilized income varies by commodity and time, with the

\footnotetext{
${ }^{3}$ For most farmers, FISI does not have any copay.

${ }^{4}$ FISI ended their coverage of apples a few months after the completion of this study.

${ }^{5}$ Until 2001, when the Financière Agricole du Québec was created, decisions related to stabilized income were made by the Ministry of Agriculture, Food, and Fisheries. Since that time, the Financière Agricole du Québec has been responsible for most of the decisions related to FISI, along with the Centre d'Études sur les Coûts de Production en Agriculture.
} 
potential for involvement of farmer's groups in some cases (FADQ, 2018). The process currently includes four mechanisms of consultation that allow for farmer involvement through the farmers union-the Union des Producteurs Agricoles. Figure 2 highlights the four mechanisms (circled). Arrows represent the relationship inside mechanisms, and square boxes identify the institutions and groups involved. In Québec, Union des Producteurs Agricoles has specific chapters-or unions-grouped by commodities produced. This research focused on each of these mechanisms of consultation to highlight their impact on the decision-making processes.

In the lower left corner of Figure 2 is the Centre d'Études sur les Coûts de Production en Agriculture (CECPA). It oversees two of the mechanisms of consultation: sectoral committees and CECPA's board. The first step in determining production cost is the meeting of each sectoral committee; there is one committee for each commodity or group of commodities. They meet every five years for about 12 to 13 months. The committees ensure that the methodology used to determine production cost is adequately applied while respecting the uniqueness of each sector. The com- position of the sectoral committees varies in number but always includes representatives from the FADQ, the Ministry, and commodity groups (CECPA, 2018).

Second, sectoral committees recommend results from the production cost studies for adoption by CECPA's board. CECPA's board must formally adopt the study once sectoral committees validate it. The board does not have the power to change the cost of production, but it can raise additional concerns or overlooked issues for discussion. This board includes equal members from Union des Producteurs Agricoles, FADQ, and the Ministry. Once the board is confident about the results, it sends the study to the FADQ, which uses the information to compute the stabilized income.

The FADQ is in the top right corner of Figure 3. It oversees the other two mechanisms of consultation: ad hoc meetings and the Financière Agricole du Québec's board. First, FADQ holds ad hoc meetings to present the stabilized income to the commodity groups. In these meetings, FADQ usually invites multiple representatives from a single commodity group to discuss the circumstances associated with the commodity's market conditions. $^{6}$

Figure 2. Institutions Involved in FISI and Their Decision-Making Bodies

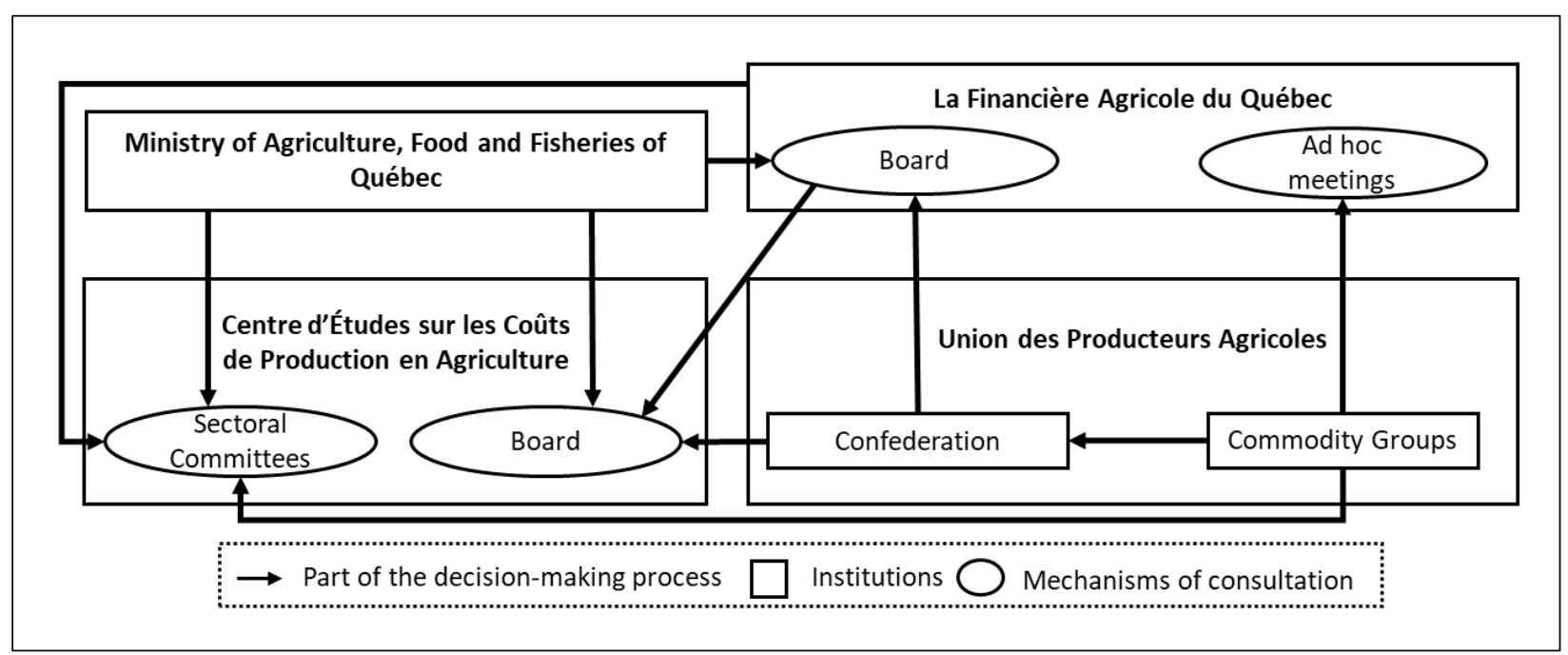

Source: Author. ${ }^{6}$ Each commodity group can also request a meeting to discuss concerns about technical elements that need to be updated or changed
to ensure the calculation represents the reality of farmers. 
Finally, FADQ's board adopts the final cost of production so it can become the major component used to compute the stabilized income. As such, the board acts as the last resort for questions that would have been left unanswered. The board includes the deputy minister, representatives from Union des Producteurs Agricoles, and representatives from civil society that are not involved in agriculture.

\section{Methods}

This paper adopted a program evaluation methodology and conducted an outcome evaluation on the mechanisms of consultation to assess stakeholders' perceptions of how each of the four mechanisms works in Québec's FISI program. This approach is appropriate when assessing the capacity of a program to achieve its intended goals or its capacity to reach some standards (Kellaghan \& Madaus, 2000; Schalock, 2007). Furthermore, applying this method to consultation mechanisms can facilitate the evaluation of different stakeholders in influencing program decision-making. By considering that the goal of each stakeholder is to influence FISI to achieve their own economic objectives (Godbout, 1983), conducting an outcome evaluation may indicate the extent to which the different stakeholders' interests are being met (Kellaghan \& Madaus, 2000) since it values the judgments of those participating in the process (Schalock, 2007).

This study included 18 semi-structured interviews conducted with stakeholders representing the four organizations involved in FISI's mechanisms of consultation. The research was conducted under the University of Arkansas IRB Protocol 1903182902. For each of the four mechanisms, at least five participants were interviewed (see Table 2 for details). Each interviewee must participate, be active in, or oversee other individuals who participate in the mechanisms of consultation. Most participants are involved in more than one mechanism, which explains the discrepancy between 18 interviewees and 33 participants in consultation mechanisms. The first round of interviews was with participants who organize meetings or supervise employees to familiarize them with this project and ask their help in identifying additional participants (McDavid et al., 2013).

A general interview guide was developed and then slightly modified so that each participant responded to questions related to their experience. Interviews were conducted in French (an English version of the interview guide is in Appendix A). As part of the interview guide design, the interviewer considered participants as experts with knowledge in their field inaccessible to members of the public (Froschauer \& Lueger, 2009). According to Wroblewski \& Leitner (2009), such participants are particularly helpful when the interview generates nonexistent data on the context of a program and the stakeholders involved in it. To increase participants' confidence and generate more detailed information regarding mechanism discussions, the interviews were not recorded. Instead, the interviewer took detailed notes regarding the key elements mentioned by participants.

The interviewer developed the interview guide and coding template for the thematic analysis of the results (Owen, 2014) based on Arnstein's ladder of citizen participation and Glasser's choice theory (see Appendix B for the full codification grid). Table 3 presents the association of interview questions with Glasser's (1999) fundamental psychosocial needs for participation.

The interviewer reviewed the material grouped in each category and each mecha- 
nism to look for similarities in participant responses. A deconstruction process was used to reduce the potential for identifying participants' codification. The data from each interview was divided into a new document to regroup all information mentioned for each theme. Identification of individual participants was kept with the information until the writing process. Some contextual information that could help the readers understand the meaning of the information was lost, but the trade-off for increased confidentiality was deemed more important since participants knew each other and received a copy of the study.

The interviewer developed themes to describe similarities as they appeared. As an example of coding elements, the theme 'Positive Climate' in the category 'Fun' for CECPA's board included 'The climate is good, meetings are positive," 7 and "This is not a negotiation mechanism but a place for exchange and understanding." Moreover, the theme
'Acceptation of Different Ideas' in the 'Belonging' category of ad hoc meetings included "Topics must be well prepared [by those bringing them to the table], this is not a banking machine," and "Smaller commodity groups need to really prepare what they are looking for with great care because they often have preconceived notions that are not backed by facts."

The themes were then used to qualify the extent, or ladder rung, that each mechanism would occupy on Arnstein's ladder of citizen participation. Each theme could have a positive, negative, or neutral contribution to each variable. Some examples of themes with positive contributions included "Positive climate," "Capacity to express ideas," and "Dynamic of the meetings." Negative examples included mentions of "Tensions," "Opposition," and "Framing of information." Neutral examples included "CECPA's role," "Direction of the board," and "Type of topics addressed."

Table 3. Association of Interview Questions With Elements of Glasser's (1999) Choice Theory

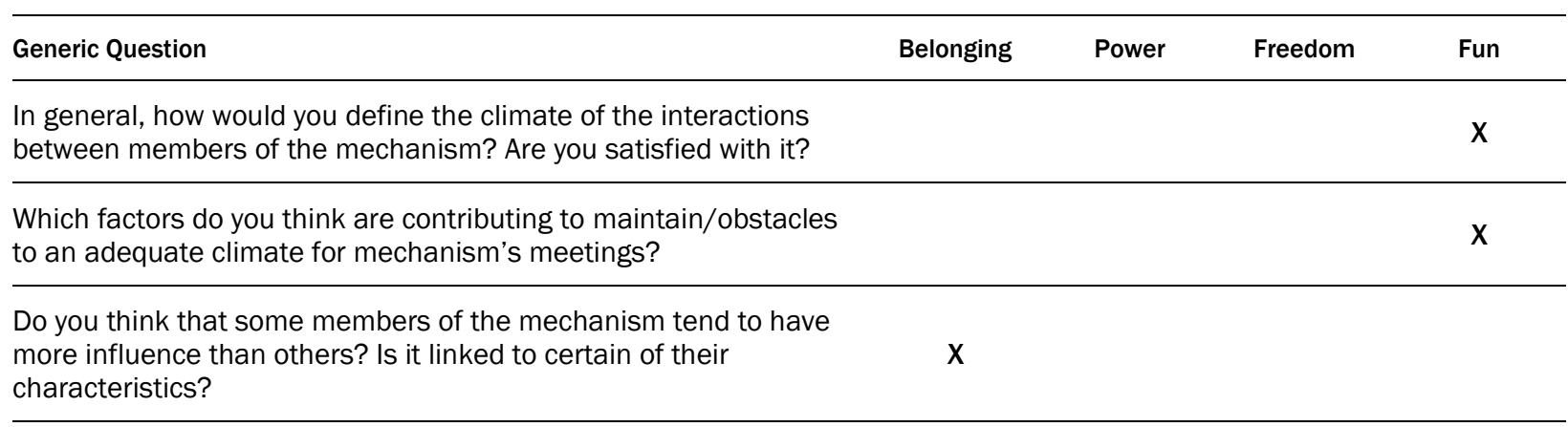

To what extent are discussions in other mechanisms of consultation and their decisions influencing the decisions in your mechanism of consultation?

$\mathrm{X}$

Do you feel that the decisions you take are generally respected by other mechanisms of consultation?

Are you generally able to influence the agenda of the discussions in your mechanism of consultation?

\begin{tabular}{l}
$\begin{array}{l}\text { Do you consider that the meetings are generally positive and help } \\
\text { you push your claims? }\end{array}$ \\
$\begin{array}{l}\text { Could some solutions be implemented to enhance the climate of } \\
\text { the mechanism's meetings? }\end{array}$ \\
\hline
\end{tabular}

\footnotetext{
${ }^{7}$ All quotes are translations of the participants' responses. Attempts were made to stay as close as possible to the syntax and word choice of the participants.
} 
Table 4. Affiliation of Interview Participants by Mechanism of Consultation

\begin{tabular}{|c|c|c|c|c|c|}
\hline \multirow[b]{2}{*}{ Affiliation } & \multirow{2}{*}{$\begin{array}{l}\text { Arnstein's Ladder of } \\
\text { Citizen Participation }\end{array}$} & \multicolumn{4}{|c|}{ Glasser's fundamental needs } \\
\hline & & Belonging & Power & Freedom & Fun \\
\hline CECPA's sectoral committees & $\begin{array}{l}\text { Between placation and } \\
\text { partnership }\end{array}$ & Strong & Weak & Strong & Strong \\
\hline CECPA's board & Partnership & Strong & Medium & Medium & Strong \\
\hline Ad hoc meetings & Informing & Weak & Weak & Medium & Medium \\
\hline FADQ's board & Consultation & Strong & Medium & Medium & Strong \\
\hline
\end{tabular}

Notes: CECPA: Centre d'Études sur les Coûts de Production en Agriculture FADQ: Financière Agricole du Québec

\section{Results}

The following section presents where each mechanism of consultation fell on Arnstein's eight-rung ladder of citizen participation and its capacity to fulfill Glasser's psychosocial needs. Table 4 summarizes each mechanism's classification following these two theories.

\section{Centre d'Études sur les Cô̂ts de Production en Agriculture's sectoral committees}

Sectoral committees are in charge of verifying that the application of production cost methodology is in line with the particularities of each sector.

Accordingly, they orient their discussions toward technical aspects of production and how to capture them. As such, the discussions are not focused on data but on the processes used to gather data.

All participants recognized that the sectoral committees are purely consultative, making suggestions to the CECPA about data collection and treatment adjustments. However, participants also indicated that the committees' conclusions always result from a consensual discussion between different parties. This combination of consultation in an attempt to reach consensus and the comments from participants makes it hard to identify the mechanism as a pure placation or partnership on Arnstein's ladder.

The partnership aspect reflects the complementary roles of each actor as identified in participants' responses. They mentioned FADQ as focused on methodology and budget control, Union des Producteurs Agricoles and commodity groups as the most vocal actors representing the preoccupations of farmers, and the Ministry's representatives as advocating for a program reflecting political orientations. Each participant mentioned that they could raise their concerns and felt that each actor played its role as intended. When talking about the relationships between committee members, conviviality, collaboration, respect, good faith, confidentiality, and constructiveness were mentioned frequently. These comments highlight a sense of participant belonging in this mechanism.

On the other side, the placation aspects of the mechanism had some impact as responses exposed participants' frustration with the relative lack of power they feel they have in the decision-making process. Specifically, the requirement to respect established methodological guidelines in the production cost study was repeatedly identified as a source of frustration by commodity groups. As an example, one participant shared the following when describing FADQ's attitude toward proposals for change: "The [Financière Agricole du Québec] is very active during the meetings. They are always quick to prevent any evolution of the study. They always want to go back to the methodological guidelines. They are perceived as grumpy."

This burden of proof requirement also limits the freedom of discussion. For instance, the tacit knowledge and anecdotal evidence offered by farmers are sometimes dismissed, according to some participants. Moreover, one participant mentioned that not all commodity groups have sufficient financial and human resources to collect the data they need to support their claims. CECPA can then supplement commodity groups by acquiring 
information through the production cost study and conducting specific analysis on demand. "It is hard to bring new data because we do not have access to it. But recently, there is an opening by [Centre d'Études sur les Coûts de Production en Agriculture] to document most questions that are raised." Moreover, other participants described the concern shown by CECPA as it listened to requests made by stakeholders. Hence, the freedom aspect appears to be present, though partially limited by FADQ's request for data-driven discussions.

Finally, participants considered that stakeholders demonstrate mutual respect and shared understanding of other members' goals. Participants shared how they trust one another and find common ground when disagreements arise. Members mentioned that the committee leader's actions drive transparency. According to one member,

There is not much room to improve the positive climate because it is going so well. Participants have a lot of experience, so it helps. So, these people-whether they are farmers or not - they know the objectives of everyone. When there is some skirmish between participants, it does not last long. Though we have to understand that it can get emotional occasionally.

\section{Centre d'Études sur les Cô̂ts de Production en Agriculture's board}

Over the years, CECPA's board has adopted and revised the methodology guidelines for the production cost studies. The board then can focus on assessing whether these guidelines were adequately followed to ensure the trustworthiness of the results.

Since each organization has seats reserved on the board and CECPA presents the information to its board members, it is possible to consider this mechanism as a partnership between stakeholders. Participants also indicated that the mechanism is one where decision-making is shared, and all perspectives and concerns are deemed valid. One participant mentioned, "It was created as a neutral entity, not affiliated to any of the stakeholders."

Participants unanimously asserted that the inclusive environment led to a feeling that repre- sentatives from diverse organizations have a voice in the process (belonging needs). It was also mentioned that board members could see beyond their own interests and focus on a shared goal. For instance, one participant said, "Everyone is [on board] for the best of [Centre d'Études sur les Coûts de Production en Agriculture] and not to act as a representative of their own organization."

Participants mentioned that meeting discussions are organized around the technical aspects of production cost studies (e.g., choice of data sources, indexes to use, modulation factors of technology usage). However, participants also identified that a singular focus on technical aspects reduced their autonomy. In terms used by Glasser, this could mean that participants feel that their needs for freedom and power are not fully met. For example, one participant noted, "If [Financière Agricole du Québec is] not convinced, it is not a good start to ensure a follow-up of the decision." Still, the board remained the mechanism in charge of adjusting the guidelines and thus had actual decision-making power. Participants also praised the capacity of the mechanism to openly share knowledge that complemented the information and suggestions shared by others. As one participant mentioned, "The diversity in stakeholders helps to bring different perspectives without creating redundancy."

Hence, it is possible to consider that a positive climate is present during the meetings without strong opposition being raised. Participants especially identified transparency and professionalism as factors sustaining beneficial, and thus fun, collaborations.

\section{Ad hoc meetings}

Ad hoc meetings are held at least once a year to review the previous year of FISI actions or address issues with the parameters of the compensation calculation. They are an informal form of consultation with the FADQ, mostly presenting information to commodity groups. In this case, one actor leads the meeting while the others listen. This structural arrangement represents Consultation, which appears in the lower half of Arnstein's ladder (rung 4 of 8). As one participant mentioned, "I feel that the Financière Agricole du Québec 
doesn't really consider farmers' input, but follows their own preferences." This structure creates a climate of negotiation that is not present in the other mechanisms and is reflected in the participants' responses, with a pronounced divergence between the higher-level participants and farmers' representatives. Higher-level participants generally mentioned that meetings were held with the idea of collaboration, a willingness to listen to different perspectives, and a generally positive and fruitful climate. On the other side, there was a recognition that individuals in the meetings are cordial; however, participants critiqued the lack of willingness to understand the different perspectives presented in the meetings, with some individuals playing a political game instead. For instance, one participant mentioned a sentiment of paternalism in the discussions. Another noted that it was important to educate the producers to focus on relevant topics when voicing their demands. Glasser's belonging needs might be negatively affected by this situation.

Moreover, the terms used by participants (e.g., paternalism, need to educate) illustrate the existence of a power gap between participants. Some participants also indicated their suggestions for change were seldom enacted. For example, one participant claimed the FADQ sometimes misrepresented one mechanism's ideas and suggestions to another. This created confusion and tension between groups, with one thinking that another had made recommendations that conflicted with theirs and hindered them from meeting their objectives. Similarly, farmers mentioned that to maintain good relations with the FADQ, they sometimes had to choose their battles, in some cases accepting the will of the FADQ so that other objectives might be met in the future. In addition to power as a fundamental need, this situation likely affects Glasser's fun need. Still, fun's limitations are to be put in perspective since participants identified the climate as professional with respect demonstrated by all actors.

Finally, the structure of the ad hoc meetings has repercussions for the freedom of the discussions, especially for smaller groups. Participants mostly involved with smaller FISI productions talked about a lower frequency of meetings and some problems encountered in getting considera- tions for their items. On the other hand, participants mostly involved with larger groups mentioned that ad hoc meetings were quite frequent and better able to realize additional inquiries. For the latter group, participants declared that they had the freedom to address various topics and be considered in their demands which seems to oppose the former group's experience.

\section{Financière Agricole du Québec's board}

The role of FADQ's board is to adopt the stabilized income (i.e., the basis for compensation). In addition, this board acknowledges the previous work of other mechanisms and acts upon their conclusions. Because Union des Producteurs Agricoles has a minority of reserved seats on the board, this mechanism can be considered a partnership between the Ministry and Union des Producteurs Agricoles.

This partnership is also reflected in participants' responses, though they mentioned that, in the past, the board's leadership questioned the Union des Producteurs Agricoles' presence on the board. One long-serving member claimed, "There were times when it was going quite awful on the board and we almost fought it out. The new chairman is knowledgeable about agriculture and wishes to have a stronger [Financière Agricole du Québec]."

Participants, however, mentioned that political decisions constrain FADQ's board. First, the Ministry and the government oversee the acts that define the scope of the FADQ's actions and FISI's intervention mechanisms. Second, participants mentioned how limited the board is in making decisions because those involving more than CA $\$ 1 \mathrm{M}$ (less than $0.2 \%$ of FADQ's budget) must be submitted to the Council of Ministers. Third, three participants from different professional backgrounds mentioned that information presented at board meetings represents the priorities of the senior executives of the FADQ rather than what was discussed in the other consultation mechanisms. Thus, even if the formal process identifies a specific role of the board regarding FISI, the answers from the participants point toward limitations and barriers to expressing this power.

Furthermore, participants suggested that if 
Union des Producteurs Agricoles strongly disagrees with a decision, it may rely on its political influence to address the Minister directly and bypass the whole consultation process. Nevertheless, the board's current leadership was praised by participants regarding the positive climate of the meetings. They specifically mentioned an environment of mutual respect and collegiality, alleviating the tension and controversy that was once present during meetings. Time also appeared to be given to board members to ensure they could fully process all the information before making a decision. One participant noted, "If a group of individuals feels uncomfortable with a proposition, or raises doubts, oftentimes the decision is postponed."

\section{Discussion}

Based on the experience of 18 participants in the four different mechanisms of consultation of Québec's FISI program, it is possible to identify emerging patterns in the capacity of these mechanisms to involve and satisfy stakeholders. Each of these patterns then affects the extent to which the fundamental needs of participants are met.

First, most mechanisms recognize the legitimacy of stakeholders regarding program decisions. Even if they appear on different rungs of Arnstein's ladder, the program's main beneficiaries at least have official recognition of their input. In public policy theories, this is not always the case (Arnstein, 1969; Schneider \& Ingram, 1993, 1997), so involving stakeholders should not be considered as systematically granted.

Second, the hierarchical arrangement of the mechanisms presented in this paper creates opportunities for the involvement of different levels of actors. For instance, in sectoral committees, commodity groups and lower-level bureaucrats participate in discussions. In contrast, on the boards, discussions involve higher-ranking individuals with senior executives of Union des Producteurs
Agricoles and Ministry. ${ }^{8}$ This arrangement allows different levels of concerns to be addressed. In sectoral committees, questions and comments are more centered on the actual reality experienced by farmers. In contrast, the subjects discussed on both boards tend to be directed toward sectoral and industry concerns. The higher-level mechanisms also allow elements that were discarded previously but are important for beneficiaries to be brought back to the table. Similarly, they provide an opportunity to share elements from one sector to another to avoid discrepancies between sectors. Hence, other mechanisms may influence how discussions are held and what subjects are addressed. This element of collaboration illustrates a form of complementarity between the rungs depicted by Arnstein.

Third, multiple mechanisms can help to compartmentalize political and technical discussions. In the case of the FISI mechanisms, the focus of discussions is highly directed toward technical aspects of the program. This approach demonstrates that elements supported by facts and research are highly valued over tacit knowledge, experience, and opinions. ${ }^{9}$ Schneider and Ingram (1997) call these programs Scientific and Professional Policy Designs. In their concept, this design reduces the involvement of beneficiaries and political elements and instead recognizes that scientists (and professionals could be added here) control the information and thus the discussions. This may present a problem for stakeholders, as it requires them to mobilize financial resources to hire experts and professionals, thus creating a barrier to entry for some actors that wish to participate in the debate. In addition, smaller commodity groups highlighted their limited capacity for the data generation necessary to sustain group discussions. However, different participants identified that CECPA's team could conduct additional research when requested by committee and board members. Actions from the neutral

\footnotetext{
${ }^{8}$ Even between the two boards, a hierarchical relationship can be observed. For instance, Centre d’Études sur les Coûts de Production en Agriculture's board involves individuals holding positions such as director and assistant deputy minister. Opposingly, on the Financière Agricole du Québec's board, individuals hold positions such as CEO and deputy ministers.

${ }^{9}$ Participants also recognized that politics had a place and that meetings were held to address less technical aspects. However, these meetings tended to be held outside of the mechanisms of consultation covered in this research, conducted through a lobbying approach by stakeholders. Still, one participant recognized that such meetings forced discussions to acknowledge political aspects.
} 
agency could then be used to improve the fulfillment of belonging and freedom needs, as discussed by Glasser.

Fourth, recurrent meetings organized into a formal schedule can support the belonging aspect for participants. This is achieved through a facilitated understanding of each participant's position. The proposal for recurrent meetings incorporates many conclusions from economic and political science theories on repeated contacts between agents and the benefits of official recognition from the state (Matthews, 2001; Williamson, 1989). In this study, many participants mentioned other participants' experiences as facilitators in the discussions and tension reducers. The fact that some participants have been involved in these mechanisms for almost 20 years also reduced the entry barrier of technical aspects as topics tend to repeat from one production study cycle to another.

Fifth, several participants identified the presence of a neutral agency, the CECPA, as a contributor in reducing the friction between actors. For instance, its leadership equalizes the position of each actor as it produces documentation to inform the discussions. However, it is important to note from participants' answers that the mere existence of a neutral agency would likely not have been a sufficient condition to achieve such leadership. Instead, participants mentioned that CECPA's attention to their concerns and its focus on involving everyone in the discussions were key factors in instituting a collaborative climate. As such, the experience and care shown by the agency staff might be as equally important as the existence of this agency.

\section{Conclusion}

This paper offered a unique perspective into the relationships between the state and stakeholders as they work on improving a long-lasting farm income support program. Based on the experience of 18 participants in the mechanisms of consultation, the paper identified solutions that can be implemented to reinforce existing programs and create some form of personal attachment to a pro- gram. It showed that a neutral agency could facilitate such relationships by reducing power gaps between actors and reinforcing their sense of belonging. Moreover, the information obtained through this agency can focus the discussion on technical aspects rather than political considerations, which is an avenue to reduce tensions between actors. However, political discussions would likely remain, and formally laying down recurrent technical and political mechanisms could increase the involvement opportunities for representatives of different hierarchical levels. It is an expectation that adopting these characteristics would help to reduce tensions inherent to a lobbyist-based relation between state and interest groups if it was replicated elsewhere. Particularly, it could foster the adoption of a climate of consensus and support stability in existing programs.

However, these conclusions are inherently embedded in the particularities of FISI's program, which include, but are not limited to, a long-lasting presence, a strong reliance on farmer's data, and an official recognition of farmers' groups by the state. Similar analyses in different program designs are required to better understand how these program characteristics may affect the relationship between actors. Unfortunately, the work between lobbyists and the state most often is conducted behind closed doors (Baumgartner et al., 2009), and these mechanisms of consultation can be quite opaque. This opacity also limits the access to actual data to document these meetings, ${ }^{10}$ which may be a barrier to replicating a similar study.

In addition, the research design of this paper only focused on the actors invited to the discussions. As such, it neglected those left outside. First, the public — through its representatives - is not involved in technical program discussions, even though public funds are used to support FISI. Second, farmers are not a monolithic group, and involving a single group in the discussions may not represent this diversity. Hence, traditionally underrepresented groups with different perspectives may not have been captured by the research design.

The conclusions presented in this paper could

\footnotetext{
${ }^{10}$ Having a neutral agency holding the discussions also had the effect of exempting these consultations from Freedom of Information requests.
} 
benefit from the additional application of the design in different programs. Specifically, a comparative approach of consultation between programs could reinforce or challenge the observed impact of a neutral agency. Similarly, it would be interesting to identify different avenues that would contribute to the segregation of political and technical discussions while involving various actors.

\section{Acknowledgments}

The author wants to thank Kenda S. Grover, Marc Bellemare, Travis Reynolds, and Clayton M. Webb for comments on previous versions of the paper. The author also wants to thank Anne B. Diallo and two anonymous reviewers for their comments and suggestions.

\section{References}

Antón, J., Kimura, S., \& Martini, R. (2011). Risk management in agriculture in Canada. OECD Food, Agriculture and Fisheries Papers, 40. http://dx.doi.org/10.1787/5kgj0d6189wg-en

Arnstein, S. R. (1969). A ladder of citizen participation. Journal of the American Planning Association, 35(4), $216-224$. https://doi.org/10.1080/01944366908977225

Bachrach, P., \& Baratz, M. (1962). Two faces of power. American Political Science Review, 56(4), 947-952. https://doi.org/10.2307/1952796

Baumgartner, F. R., Berry, J. M., Hojnacki, M., Leech, B. L., \& Kimball, D. C. (2009). Lobbying and policy change: Who wins, who loses, and why. University of Chicago Press. https://doi.org/10.7208/chicago/9780226039466.001.0001

Bellemare, M. F., \& Carnes, N. (2015). Why do members of congress support agricultural protection? Food Policy, 50, 2034. https://doi.org/10.1016/j.foodpol.2014.10.010

Beyuo, A. (2020). NGO grassroots participatory approaches to promoting sustainable agriculture: Reality or myth in Ghana's Upper-West Region? Renewable Agriculture and Food Systems, 35(1), 15-25. https://doi.org/10.1017/S1742170518000169

Bjornstad, C. S. (2009). A thematic exploration of political leadership: Relationship compatibility from the perspective of choice theory [Unpublished doctoral dissertation]. Walden University.

Blue, G., Rosol, M., \& Fast, V. (2019). Justice as parity of participation. Journal of the American Planning Association, 85(3), 363-376. https://doi.org/10.1080/01944363.2019.1619476

Brown, T. F., Swenson, S. H., \& Hertz, K. V. (2007). Identifying the relative strength of Glasser's five basic needs in school superintendents. A AS A Journal of Scholarship \& Practice, 3(4), 5-13. https:// eric.ed.gov/?id=EJ831267

Cawson, A. (1986). Corporatism and political theory. Basil Blackwell.

Centre d'Études sur les Coûts de Production en Agriculture [CECPA]. (2018). Rapport annuel 2017-2018 [Annual report 2017-2018]. Centre d'Études sur les Coûts de Production en Agriculture.

Cobb, R. W., \& Ross, M. H. (Eds.). (1997). Cultural strategies of agenda denial: Avoidance, attack, and redefinition. University Press of Kansas.

Collins, J., \& Ison, R. (2009). Jumping off Arnstein's ladder: Social learning as a new policy paradigm for climate change adaptation. Environmental Policy and Governance, 19(6), 358-373. https://doi.org/10.1002/eet.523

Commission sur l'Avenir de l'Agriculture et de l'Agroalimentaire du Québec [CAAAQ]. (2008). Agriculture et agroalimentaire: assurer et bâtir l'avenir [Agriculture and agri-food: securing and building the future]. Bibliothèque et Archives nationales du Québec.

Dahl, R. A. (1961). Who governs? Democracy and power in an American city. Yale University Press.

Daugbjerg, C., \& Swinbank, A. (2012). An introduction to the 'new' politics of agriculture and food. Policy and Society, 31(4), 259-270. https://doi.org/10.1016/j.polsoc.2012.10.002

Edwards, O. W. (2009). A choice theory teaching and learning model for working with children of prisoners. Educational Psychology in Practice, 25(3), 259-270. https://doi.org/10.1080/02667360903151833

Financière Agricole du Québec [FADQ]. (2018). Programme d'assurance stabilisation des revenus agricoles [Farm Income Stabilization Insurance Program]. Financière Agricole du Québec.

Froschauer, U., \& Lueger, M. (2009). Expert interviews in interpretive organizational research. In A. Bogner, B. Littig, \& W. Menz (Eds.), Interviewing experts (pp. 217-234). Palgrave Macmillan. https://doi.org/10.1057/9780230244276 11 
Gailmard, S., \& Patty, J. W. (2013). Learning while governing: Expertise and accountability in the executive branch. University of Chicago Press. https://doi.org/10.7208/chicago/9780226924427.001.0001

Gervais, J-P., \& Larue, B. (2007). Vers une modernisation des programmes de stabilisation et de soutien du revenu des agriculteurs québécois [Toward a modernization of Québec farm income stabilization and support program]. Commission sur l'avenir de l'agriculture et de l'agroalimentaire québécois.

Glasser, W. (1999). Choice theory: A new psychology of personal freedom. HarperCollins Publishers.

Godbout, J. T. (1983). La participation contre la démocratie. Pratiques sociales [Participation against democracy. Social practices]. Éditions coopératives Albert Saint-Martin.

Groupe de Travail sur la Sécurité du Revenu en Agriculture au Québec. (2014). Rapport final: Actualiser-développersimplifier [Final Report: Update_Expand_Simplify]. Bibliothèque et Archives nationales du Québec.

Howatt, W. A. (2011). Roles of internal locus of control and self-efficacy on managing job stressors and Ryff's six scales of psychological well-being (Publication No. 142265123) [Doctoral dissertation, Walden University]. ProQuest Dissertations Publishing.

Josling, T. (2002). Competing paradigms in the OECD and their impact on the WTO agricultural talks. In L. G. Tweeten \& S. R. Thompson (Eds.), Agricultural policy for the $21^{\text {st }}$ century (pp. 245-264). Iowa State Press. https://doi.org/10.1002/9780470390375.ch13

Kanol, D. (2015). Comparative lobbying research: Advances, shortcomings and recommendations. Journal of Public Affairs, 15 (1), 110-115. https://doi.org/10.1002/pa.1527

Kellaghan, T, \& Madaus, G. F. (2000). Outcome evaluation. In D. L. Stufflebeam, G. F. Madaus, \& T. Kellaghan (Eds.), Evaluation models: Viewpoints on educational and human services evaluation (2nd ed., pp. 97-112). Kluwer Academic Publishers. http://dx.doi.org/10.1007/0-306-47559-6

Kelman, S. (2005). Unleashing change: A study of organizational renewal in government. Brooking Institutions Press.

Lachapelle, J.-P. (2007). Rapport sur les assurances agricoles au Québec [Report on agricultural insurance in Quebec]. Commission sur l'avenir de l'agriculture et de l'agroalimentaire québécois.

Lindblom, C. E. (1959). The science of “muddling through.” Public Administration Review, 19(2), 79-88. https://doi.org/10.2307/973677

Lyngstad, M. (2020). Student and teacher perspectives on choice theory as transformative education: An alternative secondary school context [Master's thesis, Lakehead University]. Knowledge Commons.

Matthews, M. M. (2001). Cleaning up their acts: Shifts of environment and energy policies in pluralist and corporatist states. Policy Studies Journal, 29(3), 478-498. https://doi.org/10.1111/j.1541-0072.2001.tb02105.x

McDavid, J. C., Huse, I., \& Hawthorn, L. R. L. (2013). Program evaluation and performance measurement: An introduction to practice (2nd ed.). SAGE Publications.

Mercier, S. (2016). The making of a farm bill. Choices, 31(3), 1-6. https://www.jstor.org/stable/choices.31.3.11

Milford, T. M., \& Kiddell, R. B. (2020). Glasser's choice theory and science education in British Columbia. In B. Akpan \& T. Kennedy (Eds.), Science education in theory and practice (pp. 29-43). Springer Texts in Education. https://doi.org/10.1007/978-3-030-43620-9 3

Owen, G. T. (2014). Qualitative methods in higher education policy analysis: Using interviews and document analysis. The Qualitative Report, 19(26), 1-19. https://doi.org/10.46743/2160-3715/2014.1211

Schively Slotterback, C., \& Lauria, M. (2019). Building a foundation for public engagement in planning. Journal of the American Planning Association, 85(3), 183-187. https://doi.org/10.1080/01944363.2019.1616985

Schalock, R. L. (2007). Outcome-based evaluation (2nd ed.). Springer.

Schneider, A., \& Ingram, H. (1993). Social construction of target populations: Implications for politics and policy. American Political Science Review, 87(2), 334-347. https://doi.org/10.2307/2939044

Schneider, A. L., \& Ingram, H. (1997). Policy design for democracy. University Press of Kansas.

Seriès, M. (2012). Favoriser la participation en assemblée générale en répondant aux besoins des membres [Promote participation in general meetings by meeting the needs of members] [Master's thesis, Université du Québec à Montréal]. Archipel.

Skogstad, G. (2008). Internationalization and Canadian agriculture: Policy and governing. University of Toronto Press. https://doi.org/10.3138/9781442688360 
Smith, V. H., \& Glauber, J. W. (2019). The future of US farm policy. EuroChoices, 18(1), 42-48. https://doi.org/10.1111/1746-692X.12223

Stelmach, B. (2016). Parents' participation on school councils analysed through Arnstein's ladder of participation. School Leadership \& Management, 36(3), 271-291. https://doi.org/10.1080/13632434.2016.1247048

St-Pierre, M. R. (2009). Une nouvelle génération de programmes de soutien financier à l'agriculture: Pour répondre aux besoins actuels et soutenir l'entrepreneuriat [A new generation of agricultural financial support programs: To meet current needs and support entrepreneurship]. Ministère du Conseil exécutif.

Tanrikulu, T. (2014). Cyberbullying from the perspective of choice theory. Educational Research and Reviews, 9(18), 660665. https://doi.org/10.5897/ERR2014.1761

Tritter, J. Q., \& McCallum, A. (2006). The snakes and ladders of user involvement: Moving beyond Arnstein. Health Policy, 76(2), 156-168. https://doi.org/10.1016/i.healthpol.2005.05.008

Williamson, P. J. (1989). Corporatism in perspective: An introductory guide to corporatist theory. SAGE Publications.

Wroblewski, A., \& Leitner, A. (2009). Between scientific standards and claims to efficiency: Expert interviews in programme evaluation. In A. Bogner, B. Littig, \& W. Menz (Eds.), Interviewing experts (pp. 235-251). Palgrave Macmillan. https://doi.org/10.1057/9780230244276 12 


\section{Appendix A. Interview Guide}

\section{[Greetings]}

As mentioned by email, I am currently working on a research project that focuses on FISI's mechanisms of consultation. More specifically, my attempt is to map the process that is followed by recommendation for change or adjustment to FISI and to assess whether the conditions in which the discussions are happening allow for fruitful and constructive exchanges at every step of the process. To do so, I am conducting a series of interview with members of the different mechanisms of consultation. Today, I would like to talk with you about your participation in the mechanism $\mathrm{X}$ and your perception regarding the meeting of this mechanism. The whole interview process is confidential to the extent of the limits of the law and University of Arkansas' policies, and your name will not appear in the report, nor in any other communication. Moreover, you will notice that my questions do not address the actual content of the discussion you can have in the mechanism X, but rather focus on the climate surrounding these discussions. Usually, the interview process is about 30 to 45 minutes. Before I start with my questions, do you have any questions for me?

I will start with basic questions on your experience with mechanism X. Then, I will ask you questions related to your perception of the meeting in the mechanism $\mathrm{X}$ where you are involved.

- I would like to know first for how long have you participated in mechanism X?

- Mechanism X involves participants from different organization. What is the role and place of each organization in mechanism $X$ ?

- Do you think that some members of the mechanism tend to dominate the discussions? Is it linked to certain of their characteristics (e.g., gender, experience, job, organization)?

- In general, how would you define the climate of the interactions between members of the mechanism? Are you satisfied of it?

- Which factors do you think are contributing to maintain an adequate climate for mechanism's meetings?

- Which factors do you think are creating obstacles to adequate climate for mechanism's meetings?

- To what extent discussions in other mechanisms of consultation and their decisions are influencing the decisions in mechanism $X$ ? Who has the ultimate word on that?

- Do you feel that the decisions you take are generally respected by other mechanisms of consultation?

- Could some solutions be implemented to enhance the climate of mechanism's meetings? Which ones? Why?

- Are you generally able to influence the agenda of the discussions of your mechanism of consultation?

- Do you consider that the meetings are generally positive and help you push your claims?

- If I had to speak with someone else on this topic, is there anyone you think I should not miss?

This ends all the questions I had for you today. Is there anything else you would like to add regarding anything you said, or an area that was left unexplored?

[Thankful note]

As mentioned by email, you will receive a copy of my evaluation report when completed. It should be around the middle of May 2019. You will find inside of it some recommendations regarding the different mechanisms and the process of adjustment to FISI. 


\section{Appendix B.}

Table B1. Codification Grid

\begin{tabular}{|c|c|c|c|c|}
\hline \multirow[b]{2}{*}{ Categories } & \multicolumn{4}{|c|}{ Themes (as classified by mechanism of consultation) } \\
\hline & Sectoral Committees & CECPA's board & Ad Hoc Meetings & FADQ's board \\
\hline Role & - None & $\begin{array}{l}\text { - Responsibilities } \\
\text { - Utility }\end{array}$ & $\begin{array}{l}\text { - Frequency } \\
\text { - Topics addressed }\end{array}$ & - None \\
\hline $\begin{array}{l}\text { Structure of } \\
\text { Participation }\end{array}$ & - None & - None & - None & - None \\
\hline Belonging & $\begin{array}{l}\text { - FADQ's role } \\
\text { - Ministry's role } \\
\text { - Commodity Groups' } \\
\text { role } \\
\text { - CECPA's role } \\
\text { - Participation and } \\
\text { inclusion }\end{array}$ & $\begin{array}{l}\text { - UPA representatives' } \\
\text { role } \\
\text { - Ministry representa- } \\
\text { tives' role } \\
\text { - FADQ representatives' } \\
\text { role } \\
\text { - Participation and } \\
\text { inclusion }\end{array}$ & $\begin{array}{l}\text { - Acceptation of differ- } \\
\text { ent ideas } \\
\text { - Forms of the meet- } \\
\text { ings } \\
\text { - UPA representatives' } \\
\text { role } \\
\text { - FADQ representatives' } \\
\text { role }\end{array}$ & $\begin{array}{l}\text { - UPA representatives' } \\
\text { role } \\
\text { - Civil society } \\
\text { representatives' role } \\
\text { - Place of board } \\
\text { members } \\
\text { - Direction of the board }\end{array}$ \\
\hline Power & $\begin{array}{l}\text { - Limits from the meth- } \\
\text { odology } \\
\text { - Limits from the differ- } \\
\text { ences between sectors } \\
\text { - Implementation of } \\
\text { decisions } \\
\text { - Scope of discussions }\end{array}$ & $\begin{array}{l}\text { - Level of discretion } \\
\text { - Areas of influence }\end{array}$ & $\begin{array}{l}\text { - Obstacles to demands } \\
\text { for change } \\
\text { - Opportunities for } \\
\text { change }\end{array}$ & $\begin{array}{l}\text { - Framing of information } \\
\text { - Political constraints }\end{array}$ \\
\hline Freedom & $\begin{array}{l}\text { - Topics addressed } \\
\text { - Burden of proof } \\
\text { - Opposition of ideas }\end{array}$ & $\begin{array}{l}\text { - Additional inquiries } \\
\text { - Direction of the board }\end{array}$ & $\begin{array}{l}\text { - Process to request a } \\
\text { meeting } \\
\text { - Type of topics ad- } \\
\text { dressed } \\
\text { - Capacity to express } \\
\text { ideas }\end{array}$ & $\begin{array}{l}\text { - Level of preparation } \\
\text { prior to the meeting } \\
\text { - Dynamic of the } \\
\text { meetings }\end{array}$ \\
\hline Fun & $\begin{array}{l}\text { - Respect, good faith } \\
\text { and transparence } \\
\text { - Negative aspects } \\
\text { - Influence of indivi- } \\
\text { duals }\end{array}$ & $\begin{array}{l}\text { - Positive climate } \\
\text { - Respect and trans- } \\
\text { parency } \\
\text { - Opposition }\end{array}$ & $\begin{array}{l}\text { - Positive climate } \\
\text { - Political imperatives } \\
\text { - Tensions }\end{array}$ & $\begin{array}{l}\text { - Productive climate of } \\
\text { the meetings } \\
\text { - Influence of individuals }\end{array}$ \\
\hline
\end{tabular}

